\title{
A PILOT STUDY FOR PLANT THE SEED: A NUTRITION EDUCATION PROGRAM USING LOCAL FOOD ENVIRONMENT TO PUT THEORY INTO ACTION
}

\author{
KAREN A. LEE, YEON BAI, SHAHLA M. WUNDERLICH \\ Department of Health and Nutrition Sciences, Montclair State University, Montclair, NJ 07043.
}

\begin{abstract}
The purpose of this study is to implement Plant the Seed, a garden-based nutrition education program designed to reconnect children with locally grown food, food environments of the past and present, and the benefits of eating seasonal foods. The pilot study investigates environmental context and theory variables known to influence healthy food choice behavior. Social Cognitive Theory (SCT) provided a framework for the program's curriculum and evaluation. The target audience is middle school students. Plant the Seed is a two-part program. In Part 1 (classroom), students participate in practical, interactive activities based on specific educational objectives that target theory mediators. In Part 2 (field trip), students rotate through the community farm, kitchen herb garden and historic kitchen to engage in hands-on program activities. Pretest/posttest evaluation compared control and intervention students from two schools measured program effectiveness. Intervention school students $(\mathrm{n}=16)$ improved behavioral intention ( 3.40 vs $3.53, \mathrm{P}=0.34$ ), historical social norm ( 3.40 vs $3.79, \mathrm{P}=0.03$ ), and outcome expectations ( 3.91 vs $4.19, \mathrm{P}=0.03)$. No change in variables among control students $(\mathrm{n}=10)$.

Plant the Seed had a positive impact on factors associated with healthy eating behavior. This program demonstrates how to effectively engage community resources, to promote the development and implementation of gardening environments that create hands-on opportunities for children to become directly connected to local food production, to learn about the environmental benefits of eating locally grown foods and to allow children to have access to a positive, sustainable food environment. Plant the Seed can serve as a model for future theory and garden-based nutrition intervention programs.

Keywords: environmental impact, food choice behaviour, garden-based nutrition education, locally grown food, middle school students, Plant the Seed.
\end{abstract}

\section{INTRODUCTION}

For the first time ever in the United States, children are predicted to live a shorter and less healthy life than their parents [1]. Today's modern food environment encourages children to consume too many processed foods and sugar-sweetened beverages [2]. It does not support the consumption of enough health promoting foods, such as fresh, locally grown fruits and vegetables [2,3]. As a result, children have become disconnected from their agricultural roots of growing, harvesting, preparing and tasting farm fresh food [4] and how the values of sustainable farming and gardening can foster a healthful affordable food system and eating practices [5]. Children need to increase their awareness and understanding of how their food environment influences their eating habits and how our industrialized processed food system is affecting them [3,6] and destroying the earth's natural environment in which they live [7].

A growing body of research suggests nutrition education programs, integrating community and school-based gardens, are an effective way to impact eating preferences, which lead to 
the food behavior of increased consumption of health promoting locally grown foods [8-10]. These programs create access to a healthy food environment where children can actively reconnect with local food production to learn how healthy and nutritious food is grown in an environmentally conscious way [11]. An effective way to educate and empower children to develop healthy food choices, this approach further supports learning about the interconnection between sustainable food systems and environmental stewardship [12].

Garden-based nutrition education programs enable children to engage with their physical food environment and become connected to a much larger ecological system. Educating children in a local food system provides a bigger context to understand that food choices impact not only them as individuals [13]. It allows them to see how the production and consumption of locally grown foods has a positive environmental impact [5]. Increased consumption of locally grown food has significant environmental benefits. An increased demand for locally grown foods enables small farmers to expand participation in local markets to increase community access to seasonally produced food; increases financial wellbeing of small farmers; supports continued use of the land to grow food in an environmentally responsible manner that does not deplete the soil, waste water, or use environmentally harmful chemicals to fertilize or control pests [7]; reduces consumption of fossil fuels and pollution from the transportations of imported food from around the world; and reduces waste of excessive packaging that ends up in landfills [14].

Plant the Seed is a garden-based nutrition education program, designed to integrate the school classroom with a local community farm, to create a hands-on learning environment about modern day and historic food culture, local agricultural history and the benefits of eating seasonal farm fresh foods. The program aims to demonstrate the importance of contextual learning in a sustainable food environment to support desired behavior outcomes and to influence factors that lead children to make healthy food choices. This pilot study was conducted to implement this program and evaluate its effectiveness.

\section{METHODS}

Plant the Seed program was implemented in an intervention school. The intervention school was compared to the control school to assess the effectiveness of the program, using a quasiexperimental pre-test/post-test design. The Social Cognitive Theory (SCT) variables measured in this study were: behavior intention, attitude, historical social norm, physical and social environment, knowledge, outcome expectations and self-efficacy. Sixth grade students in two local northern New Jersey public middle schools participated in this study: control $(\mathrm{n}=10)$, intervention school $(n=16)$. The researcher visited the schools to explain the study objectives and sent home study information to parents. Parental consent and children's assent forms were obtained prior to the study. In the control school, 10 of 90 students returned consent and assent forms, while 16 of 42 intervention school students returned consent and assent forms. Pretests and posttests were given to both study conditions before and after the intervention program. Montclair State University's Institutional Review Board approved the study protocol. Study objectives were (1) to measure the changes in attitudes towards, and the behavioral intention of making healthy food choices, and (2) to explore the influence of theory constructs on the behavior intention of making healthy food choices among 6th grade students.

\section{INTERVENTION: PLANT THE SEED}

Plant the Seed used the Stepwise Procedural Model for Designing Theory Based Nutrition Education, a systematic process to create a behavior focused and evidence based nutrition 
education program that puts theory into action [15]. As part of the procedural model, SCT guided the development of the program's goals, objectives, lesson plans, activities and the pre/post-test survey evaluation.

The program consists of two parts: Part 1 (school) and Part 2 (field trip). Part 1 of the program entitled "What's Your Food Culture?" was an 80-minute classroom session administered one week prior to Part 2. In Part 1, students participated in a series of practical, interactive program activities based on specific educational objectives that targeted theory mediators (see Table 1).

Part 2 entitled "Be A Seasonal Whole Food Eater", was a field trip visit to a local community farm located 10 minutes from school. The field trip, 90 minutes in length, took place one week after Part 1. Upon arriving at the community farm, the whole group revisited the poster boards created in Part 1, to again compare and contrast the modern food environment with the historic food environment. This activity served to reinforce the connection between environmental influences and food choice. The students were then split into three groups and rotated through the community farm, the kitchen herb garden and the historic kitchen to participate in program activities.

\section{DATA ANALYSES}

Data from the pretest and posttest surveys were analyzed using IBM SPSS Statistics, version 21.0, IBM Corp., Armonk, NY, 2012. A Chi-square test and descriptive analysis compared the demographic characteristics between the control and intervention students. Independent t-tests were used to compare the pretest and posttest average mean scores of the measured variables between the control and intervention groups. Paired t-tests were used to compare the pretest and posttest average mean scores of the measured variables within the control and intervention groups. Type 1 error was set at $\mathrm{p}=0.05$ for all statistical analyses.

Table 1: Modified lesson plan excerpts from Plant the Seed.

\begin{tabular}{|c|c|c|}
\hline $\begin{array}{l}\text { Program } \\
\text { Session }\end{array}$ & SCT Mediator & Practical educational activity \\
\hline 1 & $\begin{array}{l}\text { Outcome } \\
\text { expectations: } \\
\text { perceived benefits }\end{array}$ & $\begin{array}{l}\text { PowerPoint slides: introduce concept your health is your } \\
\text { responsibility. Ask students to present their ideas for } \\
\text { healthy habits and what's in it for them. }\end{array}$ \\
\hline 1 & Historical social norm & $\begin{array}{l}\text { Define American foodway and food culture. Use MHS } \\
\text { timeline activity for students to brainstorm answers to } \\
\text { questions about food and food environment in } 2014 \mathrm{v} \text {. } \\
\text { 1814. Students record answers on poster board. }\end{array}$ \\
\hline 2 & Knowledge & $\begin{array}{l}\text { Students identify the growing seasons (spring, summer, } \\
\text { fall, winter) in NJ "the garden state". Ask students to } \\
\text { share what seasonal produce they are eating or growing. }\end{array}$ \\
\hline 2 & $\begin{array}{l}\text { Food \& nutrition } \\
\text { skill, self-efficacy }\end{array}$ & $\begin{array}{l}\text { Farm Rotation: Students spend } 30 \text { minutes doing } \\
\text { a guided hands-on farm chore: seeding, weeding, } \\
\text { watering, harvest or compost or chicken care. }\end{array}$ \\
\hline
\end{tabular}




\section{RESULTS}

\subsection{Between schools}

The demographic characteristics between the control and intervention students showed no significant differences. At the start of the study, the control students pretest mean scores for behavioral intention, attitude, and historical social norm were higher when compared to the intervention students. The difference in attitude $(4.09$ vs. $3.71, \mathrm{p}=0.04)$ and historical social norm (3.96 vs. $3.40, \mathrm{p}=0.005)$ were statistically significant. After the intervention, the scores for these variables were similar between the two groups (control vs. intervention): behavior intention ( 3.78 vs. $3.63, \mathrm{p}=0.65$ ), attitude ( 3.95 vs. $3.73, \mathrm{p}=0.14$ ), historical social norm (3.81 vs. 3.79, $\mathrm{p}=0.85$ ) (see Table 2).

\subsection{Within schools}

When we compared pre- and post-intervention scores, the intervention school students showed improvement in their behavior intention ( $3.40 \mathrm{vs.} 3.53, \mathrm{p}=0.34)$, increased historical social norm (3.40 vs. $3.79, \mathrm{p}=0.03$ ) and outcome expectation (3.91 vs. $4.19, \mathrm{p}=0.02)$, the last two statistically significant. Other measured variables did not show significant change or improvement post-intervention ( $\mathrm{p}>0.05$ ). For the control school students the results showed no significant changes between the pretest and posttest mean scores for all measured variables $(\mathrm{p}>0.05)$ (see Table 3$)$.

\section{DISCUSSION}

Our results demonstrate how a methodically designed program had a positive impact on theory mediators that can lead to the increased consumption of locally grown foods. Use of this type of program design, in an experimental setting, helps to identify and target variables that play an influential role known to motivate food behavior and explain factors that can lead

Table 2: Comparison of measured variables between control and intervention schools (+/- SD).

\begin{tabular}{lcccccc}
\hline & \multicolumn{3}{c}{ Pre - Test } & \multicolumn{3}{c}{ Post - Test } \\
\cline { 2 - 7 } \begin{tabular}{l} 
Measured \\
\cline { 2 - 6 }
\end{tabular} & $\begin{array}{c}\text { Control } \\
(\mathrm{n}=10)\end{array}$ & $\begin{array}{c}\text { Intervention } \\
(\mathrm{n}=16)\end{array}$ & P value & $\begin{array}{c}\text { Control } \\
(\mathrm{n}=10)\end{array}$ & $\begin{array}{c}\text { Intervention } \\
(\mathrm{n}=16)\end{array}$ & P value \\
\hline $\begin{array}{l}\text { Behavior } \\
\text { Intention }\end{array}$ & $3.81(0.43)$ & $3.45(0.70)$ & 0.19 & $3.78(0.46)$ & $3.63(0.92)$ & 0.65 \\
Attitude & $4.09(0.24)$ & $3.71(0.47)$ & $0.04^{*}$ & $3.95(0.26)$ & $3.73(0.48)$ & 0.13 \\
$\begin{array}{l}\text { Historical } \\
\text { Social } \\
\text { Norm }\end{array}$ & $3.96(0.39)$ & $3.40(0.42)$ & $0.005^{*}$ & $3.81(0.35)$ & $3.79(0.67)$ & 0.85 \\
\hline
\end{tabular}

Statistically significant $\mathrm{p}<=0.05$ level (2-tailed).

Scale: 1 = disagree very much, $2=$ disagree, $3=$ not sure, $4=$ agree, $5=$ agree very much. 
Table 3: Comparison of measured variables with-in control and intervention schools (+/-SD).

\begin{tabular}{|c|c|c|c|c|c|c|}
\hline \multirow{2}{*}{$\begin{array}{l}\text { Measured } \\
\text { variable }\end{array}$} & \multicolumn{3}{|c|}{ Control school } & \multicolumn{3}{|c|}{ Intervention school } \\
\hline & $\begin{array}{l}\text { Pre Test } \\
(\mathrm{n}=10)\end{array}$ & $\begin{array}{l}\text { Post Test } \\
(n=16)\end{array}$ & $\mathrm{P}$ value & $\begin{array}{l}\text { Pre Test } \\
(n=10)\end{array}$ & $\begin{array}{l}\text { Post Test } \\
(n=16)\end{array}$ & $P$ value \\
\hline $\begin{array}{l}\text { Behavior } \\
\text { intention }\end{array}$ & $3.82(0.43)$ & $3.84(0.49)$ & 0.79 & $3.40(0.71)$ & $3.53(0.94)$ & 0.33 \\
\hline Attitude & $4.09(0.24)$ & $3.95(0.27)$ & 0.11 & $3.71(0.47)$ & $3.73(0.48)$ & 1.00 \\
\hline $\begin{array}{l}\text { Historical } \\
\text { social norm }\end{array}$ & $3.96(0.39)$ & $3.81(0.35)$ & 0.32 & $3.40(0.42)$ & $3.79(0.67)$ & $0.03 *$ \\
\hline $\begin{array}{l}\text { Environment: } \\
\text { physical }\end{array}$ & $2.80(0.69)$ & $2.90(0.61)$ & 0.38 & $3.17(0.51)$ & $3.14(0.55)$ & 0.88 \\
\hline $\begin{array}{l}\text { Environment: } \\
\text { social }\end{array}$ & $3.45(0.41)$ & $3.53(0.35)$ & 0.53 & $3.33(0.47)$ & $3.30(0.42)$ & 0.72 \\
\hline Knowledge & $84.38(11.08)$ & $76.56(15.95)$ & 0.10 & $80.00(13.20)$ & 81.67 (14.07) & 0.63 \\
\hline $\begin{array}{l}\text { Outcome } \\
\text { expectation }\end{array}$ & $4.09(0.42)$ & $4.20(0.45)$ & 0.32 & $3.91(0.47)$ & $4.19(0.53)$ & $0.03 *$ \\
\hline Self efficacy & $4.08(0.38)$ & $4.00(0.59)$ & 0.61 & $3.74(0.68)$ & $3.50(0.72)$ & 0.29 \\
\hline
\end{tabular}

Statistically significant $\mathrm{p}<=0.05$ level (2-tailed).

Scale: 1 = disagree very much, $2=$ disagree, $3=$ not sure, $4=$ agree, $5=$ agree very much.

to behavior adoption or change [15-17]. This study further supports recent findings from a review of garden-based youth nutrition intervention programs, highlighting the need to establish a standard for program design, implementation, and evaluation [11]. A systematic approach supports effective research designs and measurable outcomes, as a way to quantify not only theory-based but also the promising impact of garden-based nutrition education programs [12].

The outcomes of this intervention impacted variables that have been linked to positive behavior change. The between school comparison showed control school students had significantly higher baseline scores for attitude and behavioral intention when compared to intervention school students. However, the gap that existed between the two groups at the start of the study was closed post intervention. Prior research which supports our findings, links behavior intention to improved food choices [18] and improved attitude towards garden grown vegetables as a result of a personal connection to food production, positively influenced behavior intention such as the increased consumption of vegetables [13, 19].

To support these influential mediators, Plant the Seed created a positive food environment to strengthen behavior outcomes [6,16]. Prelip et al. [20] suggests environmental and policy influences to be more impactful, than knowledge and attitude, on the consumption behavior of children. Plant the Seed, connected students with a physical food environment to support 
local fresh food choices as opposed to those often found in and around schools, such as vending machines or convenience stores which promote highly processed, nutrient empty foods and sugar sweetened beverages. This community connection broadens children's environmental framework to reinforce ongoing efforts to improve the food environment children live in by providing them with increased access to healthy food choices. Farm-to-school programs, school gardens and the Healthy, Hunger-Free Kids Act are ongoing examples of environmental and policy actions to bring about a positive, supportive food environment. Results from these programs are showing increases in children's consumption of locally grown foods in a healthier food environment $[12,21,22]$. Common sense suggests that a healthier food environment increases the opportunity for children to establish healthy food choices, an essential ingredient for the formation of life long food habits [6, 23]. Thus, the change in attitude and behavioral intention for the intervention students suggests the environmental context created by linking the community resource of a local farm successfully impacted theory mediators known to motivate behavior intention.

The set of variables Plant the Seed impacted for intervention school students was the positive change apparent in historical social norm and outcome expectations. Historical social norm measured the unique historical focus of the program looking at the contextual influences of a modern verses historic food environment for making healthy food choices. Connecting the hands-on community farm experience with the classroom created a positive physical food environment to influence and support children's food choice behavior $[12,16]$. Educating children on the benefits of producing and eating locally grown foods, through active participation in sustainable food systems, deepens their connection, appreciation and respect for the land $[5,24]$. Their experience of planting a seed is no longer just about the vegetable plant, but an expanded relationship between the student, the environment that will produce food and its value to the community $[5,13]$. The environmental context of the community farm experience further created an acceptable social context for adolescents who are more influenced by peer preferences and poor food choices at this developmental stage $[16,19,25]$.

Outcome expectations connected children with where food comes from, how it grows and the subsequent health benefits of eating farm fresh foods and the associated risk of disease with modern day processed food choices. The importance of impacting this mediator is the influential role of personal incentives for making a desired food choice [17]. Ratcliffe et al. [16], found similar positive impact showing improvement in theory related factors: increased ability to identify vegetables and an increased preference for vegetables that led to the desired behavior of increased consumption in the variety of vegetables at school.

\section{LIMITATIONS}

This study is not without its limitations. The study took place in northern New Jersey and connected a unique resource of a community farm situated on the property of a local historical society. It may be difficult to replicate this particular setting. The quasi-experimental design utilized subjects nested within a school setting and does not permit a randomized selection of study students. Subjects were self-selected and may have had a predetermined interest in food and gardening. The small sample size was due to a lack of returned parental consent and student assent forms. Study participation may have benefited from improved study promotion and a more thorough explanation to parents and teachers. Future studies should consider this along with other distribution and return methods for parents to increase the opportunity for greater study participation. The short duration of the actual intervention 
could explain the lack of impact on more targeted variables within the intervention condition. Replicating this study in more schools would be useful to validating study results.

\section{IMPLICATIONS FOR RESEARCH AND PRACTICE}

Plant the Seed, a garden-based nutrition education program, connects the school classroom and a community farm in a partnership to foster learning about the environmental context in which children live, learn, and eat. This program demonstrates how to effectively engage community resources, 1) to promote the development and implementation of gardening environments that create hands-on opportunities for children to become directly connected to local food production, 2) to learn about the environmental benefits of eating locally grown foods and 3) to allow children to have access to a positive, sustainable food environment to support the desired behavior of increased consumption of seasonal farm fresh foods. Development of garden-based nutrition education programs, such as Plant the Seed, also supports future research and insight of the theory-mediated constructs that play important influential roles towards food choice behavior. This study adds to the small but growing body of evidence based research and can be used as a model for future theory- and garden-based nutrition education programs.

\section{REFERENCES}

[1] National Academies. U.S. health in international perspective: Shorter lives, poorer health. Website, Washington, DC, available at http://sites.nationalacademies.org/ DBASSE/CPOP/US_Health_in_International_Perspective/index.htm\#.UU3XcaVIjM8

[2] Center for Prevention and Disease Control, Youth risk behavior surveillance United States 2011, MMWR Surveillance Summaries Website, Atlanta GA, http://www.cdc. gov/mmwr/pdf/ss/ss6104.pdf

[3] Ebbling, C.B., Pawlak, D.B. \& Ludwig, D.S., Childhood obesity: public health crisis, common sense cure. Lancet. 360, pp. 473-482, 2002. http://dx.doi.org/10.1016/S0140-6736(02)09678-2

[4] Hayden-Smith, R., Soldiers of the soil: a historical review of the United States school garden army. Monograph. Web Site, Davis, CA available at http://4h.ucanr.edu/ files/1227.pdf

[5] Burns, H. \& Miller, W., The learning gardens laboratory: teaching sustainable food systems through unique partnerships. Journal of Agriculture, Food Systems, and Community Development, 2(3), pp. 69-78, 2012. http://dx.doi.org/10.5304/jafscd.2012.023.003

[6] Kane, D., What's for lunch? A review of school food and garden based-education in the United States using Portland public schools as a model for change, Website, Portland OR, available at http://www.ecotrust.org/farmtoschool/downloads/2008_05_Whatsfor-Lunch.pdf

[7] ATTRA, Sustainable agriculture: an introduction, available at https://attra.ncat.org/ attra-pub/summaries/summary.php?pub=294

[8] Morgan, P.J., Warren, J.M., Lubans, D.R., Saunders, K.L., Quick, G.I. \& Collins, C.E., The impact of nutrition education with and without a school garden on knowledge, vegetable intake and preferences and quality of school life among primary school students. Public Health Nutrition, 13(11), pp. 1-10, 2010. http://dx.doi.org/10.1017/S1368980010000959 
[9] Morris, J.L. \& Zidenberg-Cherr, S.Z., Garden-enhanced nutrition curriculum improves fourth-grade school children's knowledge of nutrition and preferences for some vegetables. Journal of the American Dietetic Association, 102(1), pp. 91-93, 2002. http://dx.doi.org/10.1016/S0002-8223(02)90027-1

[10] Robinson-O'Brien, R., Story, M. \& Heim, S., Impact of garden-based youth nutrition intervention programs: a review. Journal of the American Dietetic Association, 109(2), pp. 273-280, 2009. http://dx.doi.org/10.1016/j.jada.2008.10.051

[11] Mayer-Smith, J., Bartosh, O. \& Peterat, L., Teaming children and elders to grow food and environmental consciousness. Applied Environmental Education and Communication, 6(1), pp. 77-85, 2007. http://dx.doi.org/10.1080/15330150701319529

[12] Scherr, R.E., Cox, R.J., Feenstra, G. \& Ziedenberg-Cherr, S., Integrating local agriculture into nutrition programs can benefit children's health. California Agriculture, 67(1), pp. 30-37, 2013. http://dx.doi.org/10.3733/ca.v067n01p30

[13] Blair, D., The child in the garden: an evaluative review of the benefits of school gardens. The Journal of Environmental Education, 40(2), pp. 15-38, 2009. http://dx.doi.org/10.3200/JOEE.40.2.15-38

[14] Food miles: how far your food travels has serious consequences for your health and the climate, available at www.farmlandinfo.org/food-miles-how-far-your-food-travels-hasserious-consequences-your-health-and-climate

[15] Contento, I.R., Nutrition Education: Linking Research, Theory, and Practices, 2nd edn., Jones and Barlett: Sudbury, MA, 2011.

[16] Ratcliffe, M.M., Merrigan, K.A., Rogers, B.L. \& Goldberg, J.P., The effects of school garden experiences on middle school-aged students' knowledge, attitudes and behaviors associated with vegetable consumption. Health Promotion Practice, 12(1), pp. 36-43, 2011. http://dx.doi.org/10.1177/1524839909349182

[17] Anderson, E.A., Winett, R.A. \& Wojcik, J.R., Self-regulation, self-efficacy, outcome expectations, and social support: social cognitive theory and nutrition behavior. Annals of Behavior Medicine, 34(3), pp. 304-312, 2007.

http://dx.doi.org/10.1007/BF02874555

[18] Dollahite, J., Hosig, K.W., White, K.A., Rodibaugh, R. \& Holmes, T.M., Impact of a school-based community intervention program on nutrition knowledge and food choices in elementary school children in the rural Arkansas delta. Journal of Nutrition Education, 30(5), pp. 289-301, 1998. http://dx.doi.org/10.1016/S0022-3182(98)70338-3

[19] Somerset, S. \& Markwell, K., Impact of a school-based food garden on attitudes and identification skills regarding vegetables and fruit: a 12-month intervention trial. Public Health Nutrition, 12(2), pp. 214-221, 2009.

http://dx.doi.org/10.1017/S1368980008003327

[20] Prelip, M., Kinsler, J., Le Thai, C., Erausquin, J.T. \& Slusser, W., Evaluation of a school-based multi-component nutrition education program to improve young children's fruit and vegetable consumption. Journal of Nutrition Education and Behavior, 44(4), pp. 310-318, 2012.

http://dx.doi.org/10.1016/j.jneb.2011.10.005 
[21] U.S. Department of Agriculture. Fact Sheet: Healthy, hunger-free kids act school meals implementation, Web site, Washington, DC, available at http://www.fns.usda.gov/ pressrelease/2014/009814

[22] Berlin, L., Morris, K., Kolodinsky, J. \& Nelson, A., The role of social cognitive theory in farm-to-school-related activities: Implications for child nutrition. Journal of School Health, 83(8), pp. 589-595, 2013.

http://dx.doi.org/10.1111/josh.12069

[23] McAleese, J.D. \& Rankin, L.L., Garden-based nutrition education affects fruit and consumption in sixth-grade adolescents. Journal of American Dietetic Association, 107(4), pp. 662-665, 2007.

http://dx.doi.org/10.1016/j.jada.2007.01.015

[24] Ozer, E.J., The effects of a school garden on students and schools: Conceptualization and considerations for maximizing healthy development. Health Education and Behavior, 34, pp. 846-863, 2007. http://dx.doi.org/10.1177/1090198106289002

[25] Lewis, M., Brun, J., Talmage, H. \& Rasher, S., Teenagers and food choices: the impact of nutrition education. Journal of Nutrition Education, 20(6), pp. 336-340, 1988. http://dx.doi.org/10.1016/S0022-3182(88)80017-7 